\title{
Diode laser crystallization processes of Si thin-film solar cells on glass
}

\author{
Jae Sung Yun ${ }^{1, a}$, Cha Ho Ahn ${ }^{1}$, Miga Jung ${ }^{1}$, Jialiang Huang ${ }^{1}$, Kyung Hun Kim ${ }^{1,2}$, \\ Sergey Varlamov ${ }^{1}$, and Martin A. Green ${ }^{1}$ \\ 1 University of New South Wales, NSW, 2033, Kensington, Australia \\ 2 Suntech R\&D Australia, Pty., Ltd. 82-86 Bay St., BSW 209, Botany, Australia
}

Received: 30 July 2013 / Received in final form: 20 November 2013 / Accepted: 6 January 2014 Published online: 7 July 2014

(C) Yun et al., published by EDP Sciences, 2014

\begin{abstract}
The crystallization of Si thin-film on glass using continuous-wave diode laser is performed. The effect of various processing parameters including laser power density and scanning speed is investigated in respect to microstructure and crystallographic orientation. Optimal laser power as per scanning speed is required in order to completely melt the entire Si film. When scan speed of $15-100 \mathrm{~cm} / \mathrm{min}$ is used, large linear grains are formed along the laser scan direction. Laser scan speed over $100 \mathrm{~cm} / \mathrm{min}$ forms relatively smaller grains that are titled away from the scan direction. Two diode model fitting of Suns- $V_{\text {oc }}$ results have shown that solar cells crystallized with scan speed over $100 \mathrm{~cm} / \mathrm{min}$ are limited by grain boundary recombination $(n=2)$. EBSD micrograph shows that the most dominant misorientation angle is $60^{\circ}$. Also, there were regions containing high density of twin boundaries up to $\sim 1.2 \times 10^{-8} / \mathrm{cm}^{2}$. $\mathrm{SiO}_{x}$ capping layer is found to be effective for reducing the required laser power density, as well as changing preferred orientation of the film from $\langle 110\rangle$ to $\langle 100\rangle$ in surface normal direction. Cracks are always formed during the crystallization process and found to be reducing solar cell performance significantly.
\end{abstract}

\section{Introduction}

Polycrystalline silicon thin-film solar cells on glass are strong candidate for next generation photovoltaic technology as it combines advantages of both wafer Si solar cells technology and thin-film solar cells technology. Si material has advantages of nontoxicity and low-cost. Commercial polycrystalline silicon thin-film solar cells have been fabricated by CSG Solar which achieved photovoltaic conversion efficiency of $10.4 \%$ in 2007 [1]. In this solar cell, $2 \mu \mathrm{m}$ thick a-Si thin-films on borosilicate glass were crystallized using solid phase crystallization (SPC) process which produced grain sizes in the range of 1-2 $\mu \mathrm{m}$. However, high density of intragrain defects are generated during the SPC process and it was found to be lifetime limiting recombination pathway which greatly limit the open-circuit voltage [2]. Alternate to SPC, it was reported that continuouswave $(\mathrm{CW})$ diode laser crystallization of Si thin-film on glass can form defect-free grains with very large grains size up to few tenths of millimeters in length [3]. Performance potential of this solar cells has shown that photovoltaic conversion efficiency above $13 \%$ can be achieved with a diffused homo-junction emitter [4].

\footnotetext{
${ }^{a}$ e-mail: j.yun@student.unsw.edu .au
}

In this work, the diode laser crystallization processes of Si thin-film on glass are reported in detail. Grain microstructure and crystallographic orientation were investigated in terms of the laser parameters. Then, effect of $\mathrm{SiO}_{x}$ capping layer is investigated in terms of the crystallization parameters and crystal orientation. Finally, cracks in the film are discussed and their influence on solar cell performance is evaluated.

\section{Experiment}

On a $3.3 \mathrm{~mm}$ thick planar borosilicate glass (Schott Borofloat33) with an area of $50 \times 50 \mathrm{~mm}, \mathrm{SiO}_{x} 100 \mathrm{~nm}$ thick barrier layer was deposited by plasma-enhanced chemical vapor deposition (PECVD) at $200-300{ }^{\circ} \mathrm{C}$, below $1 \mathrm{mT}$ at deposition rates of $5-30 \mathrm{~nm} / \mathrm{min}$. Then, the $\mathrm{SiO}_{x}$ layer was subjected to a dehydrogenation annealing step at $500{ }^{\circ} \mathrm{C}$ for $2 \mathrm{~h}$ under $\mathrm{N}_{2}$ flow. $10 \mu \mathrm{m}$ thick Si films were deposited by e-beam evaporation at 350 $650{ }^{\circ} \mathrm{C}$. During the deposition, in-situ boron doping was performed to realize a boron concentration of $\sim 5 \times 10^{15}$ to $\sim 2 \times 10^{16} \mathrm{~cm}^{3}$. The Si films were placed on pre-heated stage at $650{ }^{\circ} \mathrm{C}$ for $3 \mathrm{~min}$. Subsequently, CW diode laser (FWHM, $0.17 \mathrm{~cm}$ wide and $12 \mathrm{~cm}$ long) was scanned perpendicular to the $5 \mathrm{~cm}$ long axis for crystallization. After 

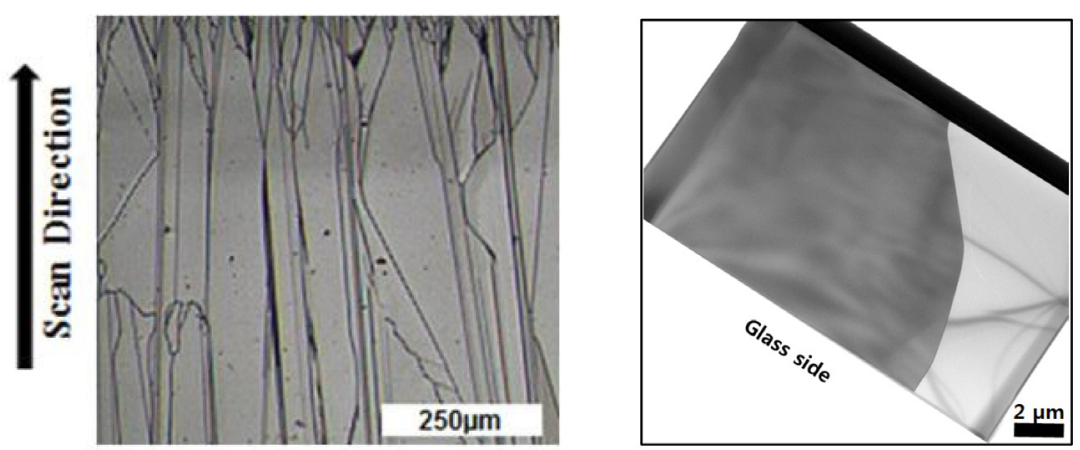

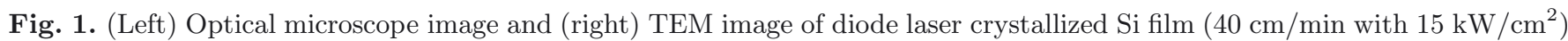
with complete melting of entire film.
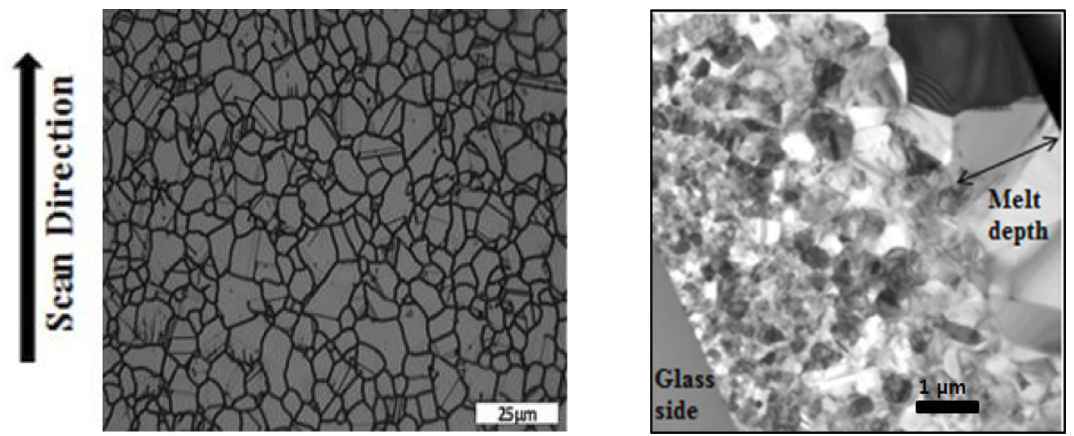

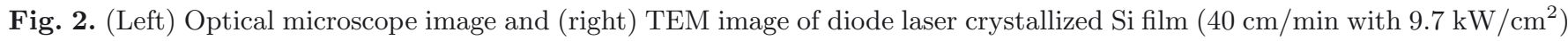
with partial melting of film.

removal of native oxide formed during the crystallization by HF dip, phosphorous dopant source (P508, Filmtronics, Inc.) was spin-coated. Subsequently, rapid thermal process (RTP) was conducted at $870{ }^{\circ} \mathrm{C}$ for 2 min. Junction depth around $500 \mathrm{~nm}$ was achieved and emitter sheet resistance of 300-500 ohms/ $\square$ was obtained. The hydrogen passivation was applied through remote plasma passivation at $\sim 650{ }^{\circ} \mathrm{C}$ for 20 min. Point contact metallization method is applied as described in reference [5].

The crystallographic orientation was analyzed by X-ray diffraction (XRD). Philips X'Pert MRD 4-circle diffractometer using $\mathrm{Cu}-\mathrm{K}_{\alpha}$ radiation. Receiving slit of $7 \mathrm{~mm}^{2}$ was used and (100), (110), (111), and (422) pole figures were measured with background subtraction. Samples were placed in the center of an open three axes goniometer in Bragg orientation up to $75^{\circ}$ tilting angle. Measurement time per step was between 5 and $10 \mathrm{~s}$, step size for both rotation and tilting was $5^{\circ}$. The data was corrected and analyzed using X'pert Texture (Version 1.1a) software which can generate pole figures and inverse pole figure maps. For high resolution electron beam scattering diffractometer (EBSD) measurement, a NordlysF detector EBSD analytical system interfaced to a Carl Zeiss AURIGA ${ }^{\circledR}$ CrossBeam ${ }^{\circledR}$ workstation was used.

\section{Results and discussion}

\subsection{Liquid phase crystallization of Si film}

Figures 1 and 2 are showing two distinctly different microstructures after Secco etching and the corresponding
TEM images of the laser crystallized Si thin-films. In our diode laser system, laser scan speed $(\mathrm{cm} / \mathrm{min})$ and power density $\left(\mathrm{W} / \mathrm{cm}^{2}\right)$ are two major parameters that control the crystallization process. Appropriate laser power density is required to completely melt the entire film [3]. Figure 1 represents the desired microstructure with large linear grains grown parallel to the laser scan direction when scan speed of $40 \mathrm{~cm} / \mathrm{min}$ with laser power density of $15 \mathrm{~kW} / \mathrm{cm}^{2}$ is used. Corresponding TEM image shows defect-free grains that were formed by complete melting of the film. Grain size can be up to few tenths of millimeters in length and several nanometers to several hundred microns in width. On the other hand, if the power density is insufficient to melt the entire film, only surface melting occurs and generates columnar grains several microns in size as shown in Figure 2. In this case, scan speed of $40 \mathrm{~cm} / \mathrm{min}$ with laser power density of $9.7 \mathrm{~kW} / \mathrm{cm}^{2}$ is used. Corresponding TEM image of partially melted Si film shows the formation of columnar grains at the surface which extends few microns into the film. If the power density is higher than the required power to achieve fullmelting, film delamination takes place.

Figure 3 is EBSD micrographs and corresponding misorientation charts of the completely melted films that were scanned at $40 \mathrm{~cm} / \mathrm{min}$ at $15 \mathrm{~kW} / \mathrm{cm}^{2}$. Due to the top-hat profile of the laser beam, intensity at the edges of the laser traces is not sufficient to achieve full-melting and form small columnar grains as shown in Figure 3a. The corresponding misorientation chart is showing that there are variety misorientation angles with relatively higher number of $60^{\circ}$ misorientation. As the intensity of the beam 
J.S. Yun et al.: Diode laser crystallization processes of Si thin-film solar cells on glass

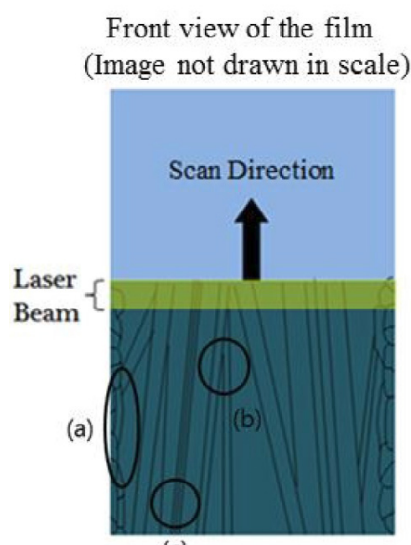

(c)
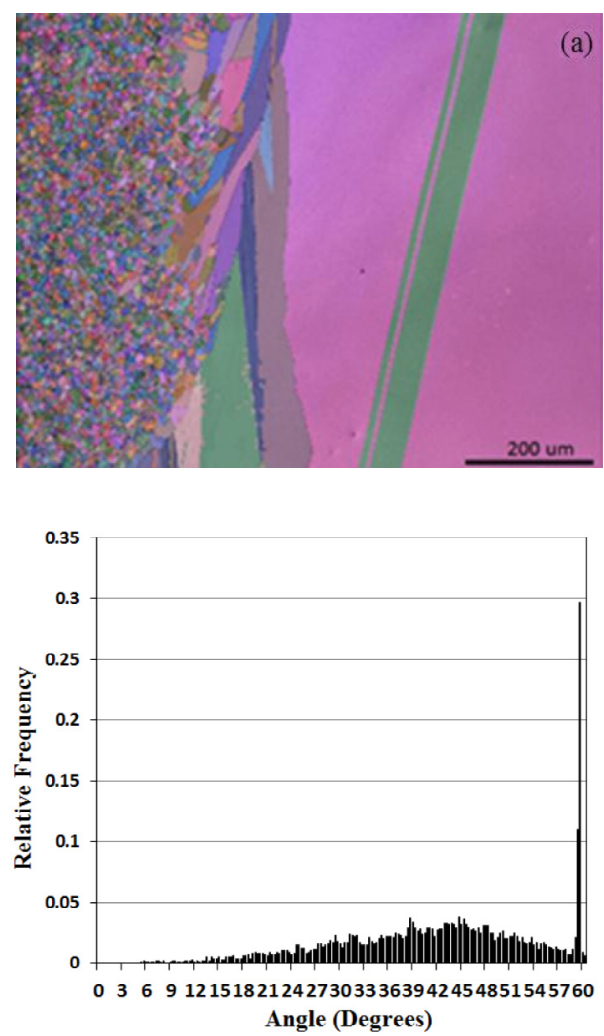
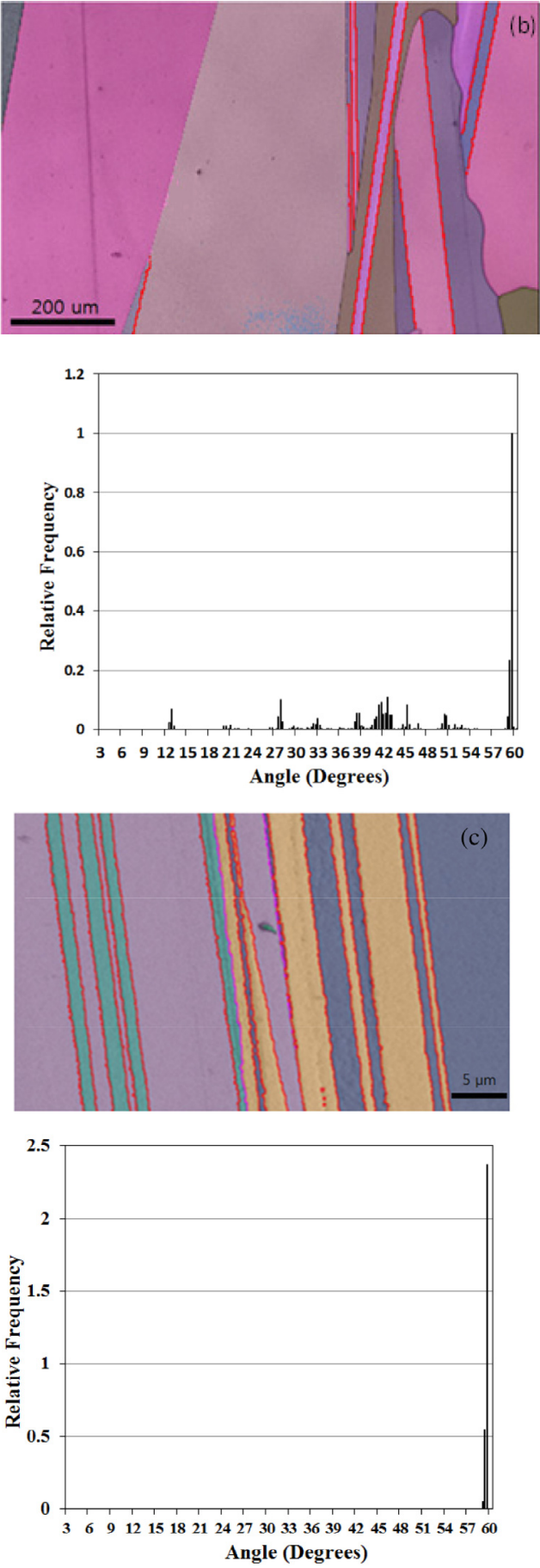

Fig. 3. EBSD micrographs and corresponding charts showing the relative frequency corresponding to each misorientation value of the laser crystallized films (40 cm/min with $15 \mathrm{~kW} / \mathrm{cm}^{2}$ ) showing (a) small columnar grains at left edge; (b) parallel grains meet each other; and (c) twin boundaries. Note that red lines represent twin boundaries.

gets stronger towards the middle region, the melt depth increases and the film becomes liquid phase. As the laser scans, this liquid Si solidifies along with, it forming large linear grains along the scan direction. Figure $3 \mathrm{~b}$ is showing termination of growth of such linear grains when adjacent grains meet each other. If the grains do not converge, they can grow continuously until the scan stops. Such parallel grains have $60^{\circ}$ misorientation angles which are marked in red lines. Frequently, there are regions where high density of parallel grain boundaries, up to $\sim 1.2 \times 10^{-8} / \mathrm{cm}^{2}$, are formed, as shown in Figure 3c. All of these boundaries are found to be $60^{\circ}$ misorientation as shown in corresponding relative misorientation chart and large number of these boundaries are found to be first order $\Sigma 3$ twin boundaries. 


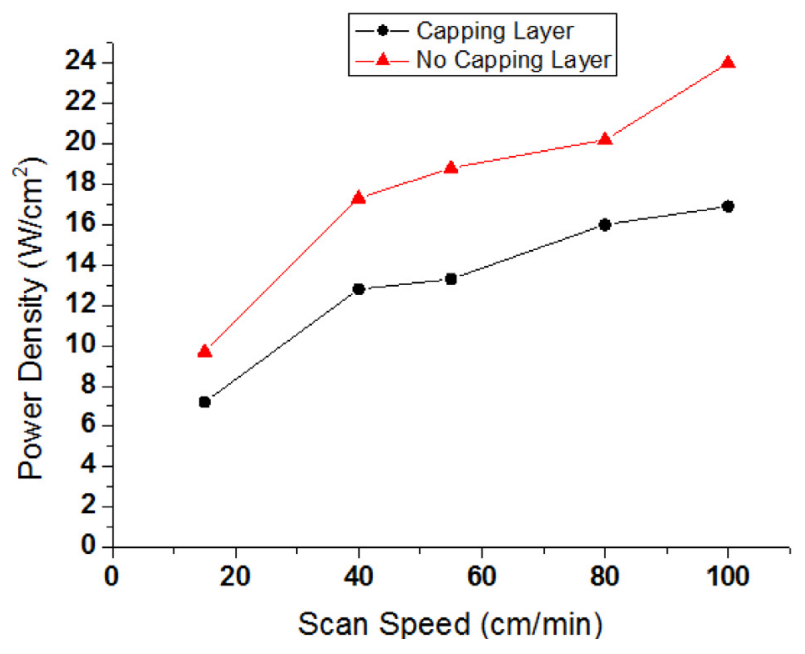

Fig. 4. Required laser power density to achieve full-melting of Si film vs. laser scan speed with and without capping layer.

\subsection{Effect of $\mathrm{SiO}_{x}$ capping layer}

In laser processing of Si film, few hundred nanometers thick $\mathrm{SiO}_{x}$ capping layer is often deposited on top of the Si film in order to enlarge grain size of the film [6]. When $100 \mathrm{~nm}$ thick $\mathrm{SiO}_{x}$ capping layer is deposited by PECVD, the required power density for full-melting of the film is reduced due to an antireflection effect. Figure 4 is an empirically obtained graph showing the required laser power density to achieve full-melting as a function of scan speed with and without capping. As can be seen from this graph, the required power density is lower when the capping layer is used. This can be explained by an antireflection characteristic of the $\mathrm{SiO}_{2}$ layer which enhances the absorption of the laser power. Our measurement shows that absorption at $808 \mathrm{~nm}$ is increased from $56 \%$ to $65 \%$. In addition to the enhanced absorption, the capping layer stores some of generated heat during the laser irradiation and the heat flows back into the Si film which elevates temperature of the film [7].

Pole figure measurements are performed using XRD and Figure 5 is showing $x$ (surface normal), $y$ (scan direction), and $z$ (plane normal) inverse pole figure maps of completely melt Si film with and without the capping layer. As can be seen, when there is no capping layer, (110) preferential orientation in $z$ direction is present. Also, there is a maximum intensity present at (112) orientation for both $x$ and $y$ directions. Although this type of orientations is not uniformly distributed all over the crystallized area, it is a very common crystallographic orientation distribution in our film. When the capping layer is applied, (100) preferential orientation is found in $z$ direction. Highest intensity at (110) orientation is formed along the $x$ direction while highest intensity is found at (111) orientation in $y$ direction. According to Atwater et al. [8], the interfacial energy at the interface between $\mathrm{SiO}_{2}$ intermediate layer and $\mathrm{Si}$ film determines the (100), (110), and (111) preferential orientation in plane normal of the Si film. The interfacial energy depends on heat flow

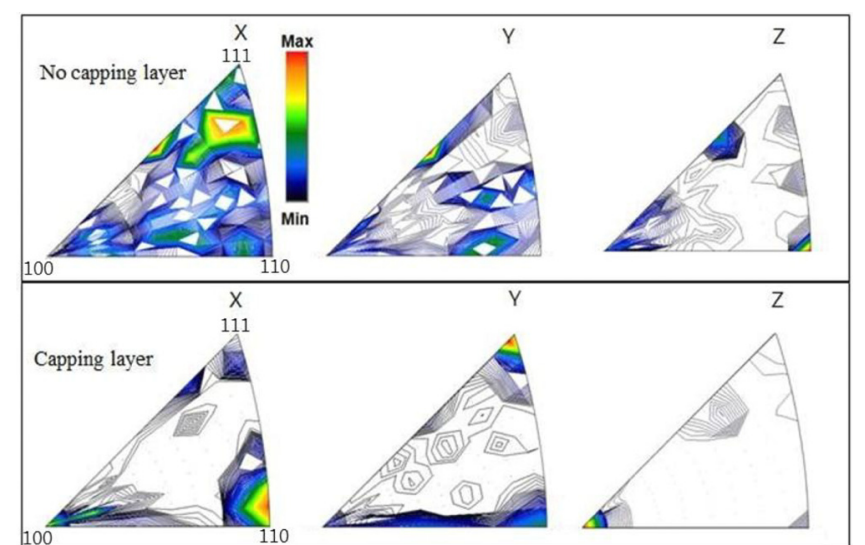

Fig. 5. Inverse pole figure maps of completely melt Si film at scan speed of $80 \mathrm{~cm} / \mathrm{min}$ with and without the capping layer.

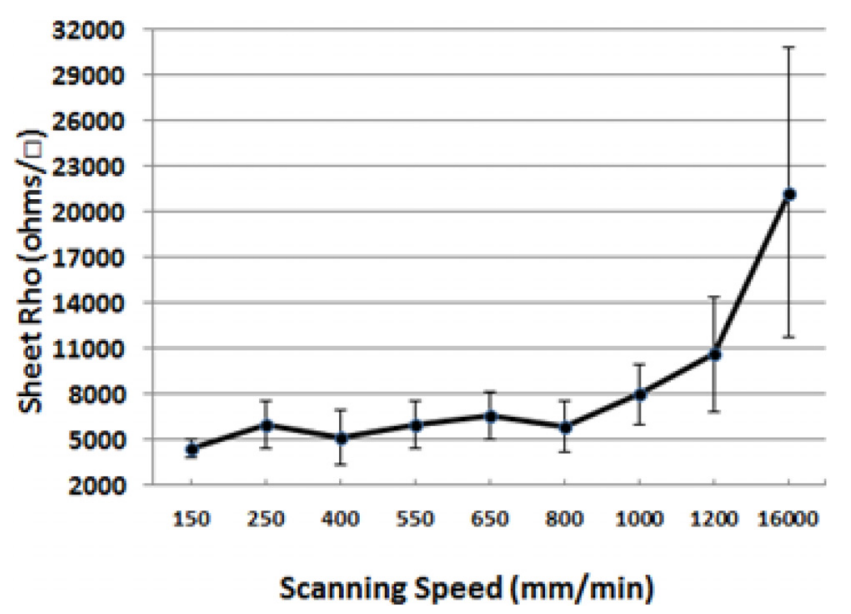

Fig. 6. Sheet resistance as function of scan speed.

during crystallization process and (100) orientation requires longest melt duration [9]. As mentioned earlier, the capping layer elevates temperature of the film and thereby it has effect of extending duration of liquid state. As a result, the (100) preferred orientation formation could have been allowed by extended melt duration in our case.

\subsection{Effect of laser scan speed}

Figure 6 is a graph of sheet resistance as function laser scan speed. The sheet resistance is almost comparable for the scan speed between $15-80 \mathrm{~cm} / \mathrm{min}$. However, the sheet resistance starts to increase from $80 \mathrm{~cm} / \mathrm{min}$ and further more rapidly from $100 \mathrm{~cm} / \mathrm{min}$. Microstructure of the laser crystallized films scanned at $40 \mathrm{~cm} / \mathrm{min}$ and $160 \mathrm{~cm} / \mathrm{min}$ is shown in Figure 7. As can be seen, grains are severely tilted away from the scan direction when $160 \mathrm{~cm} / \mathrm{min}$ is used. Figure 7 is a schematic illustration of these two grain growth behaviors. Zone 1 is liquid phase and Zone 2 is a phase transition region where liquid $\mathrm{Si}$ is in cooling stage. Zone 3 refers to a solid phase region with very high surface temperature. As can be seen, area of the Zone 2 is much larger in Type I compared to Type II. Due to excessively 

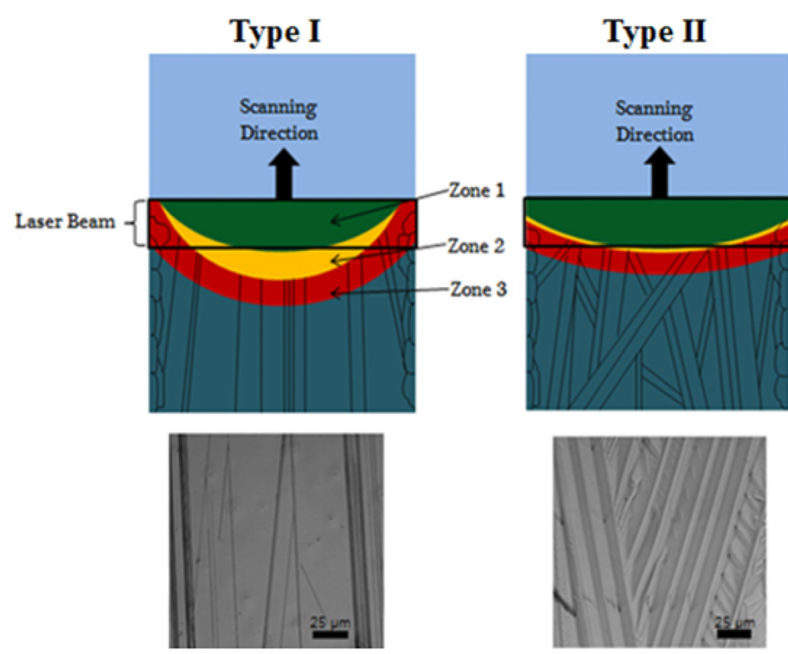

Fig. 7. Schematic illustration of grain growth behavior on two distinct scan speed regimes. Type I refers to scan speed of $15-100 \mathrm{~cm} / \mathrm{min}$ and Type II refers to scan speed over $100 \mathrm{~cm} / \mathrm{min}$.

fast scan speed in Type II, temperature in this region decreases rapidly. Therefore, molten Si quickly transforms into solid phase. As a result, grain growth cannot follow the scan direction and thus forms in random directions. Wherease, Type I provides long enough time for grain formation thereby grain growth can proceed along the scan direction.

Emitter was formed on these two types of microstrucures and Suns- $V_{\text {oc }}$ was measured after removing some portion of emitter to make contact with the absorber. Figure $8 \mathrm{a}$ is showing the obtained data and fitted curve of solar cells that were crystallized at scan speed of $40 \mathrm{~cm} / \mathrm{min}$ with $15 \mathrm{~kW} / \mathrm{cm}^{2}$. Suns- $V_{\text {oc }}$ curves are useful to identify diode properties such as open-circuit voltage, pseudo fill factor, diode ideality factors, etc., and to determine the effects of bulk and depletion region recombination [10]. Obtained data is fitted to two-diode model $(n=1$ and $n=2$ ) in order to obtain parameters $V_{o c}, V_{1}, V_{2}$ and $R_{s h}$. Detailed fitting analysis is described in elsewhere [11]. Two charactersitic voltages $V_{1}$ and $V_{2}$ are obtained at the intersection of the two fitted curves for the $n=1$ and $n=2$ diodes correspondingly with the horizontal line at 1-Sun light intensity. Generally, the $n=2$ diode $\left(V_{1}>V_{2}\right)$ accounts for SRH (Shockley-Read-Hall) recombination in the junction space charge region and at grain boundaries, whereas the $n=1$ diode $\left(V_{1}<V_{2}\right)$ accounts for bulk and surface recombination.

As depicted in Figure 8b, 1 and 0.1 Suns- $V_{o c}$ were $525.9 \mathrm{mV}$ and $445.9 \mathrm{mV}$ for the laser crystallized solar cells at $40 \mathrm{~cm} / \mathrm{min}$ and $160 \mathrm{~cm} / \mathrm{min}$, respectively. It is also shown that $n=1$ recombination $\left(V_{1}<V_{2}\right)$ is dominant for the $40 \mathrm{~cm} / \mathrm{min}$ sample, while $n=2$ recombination $\left(V_{1}>V_{2}\right)$ is dominant for the $160 \mathrm{~cm} / \mathrm{min}$ sample. Presumably, the grain boundaries tilted away from scan direction formed in $160 \mathrm{~cm} / \mathrm{min}$ act as a carrier recombination center and limits the solar cell performance.

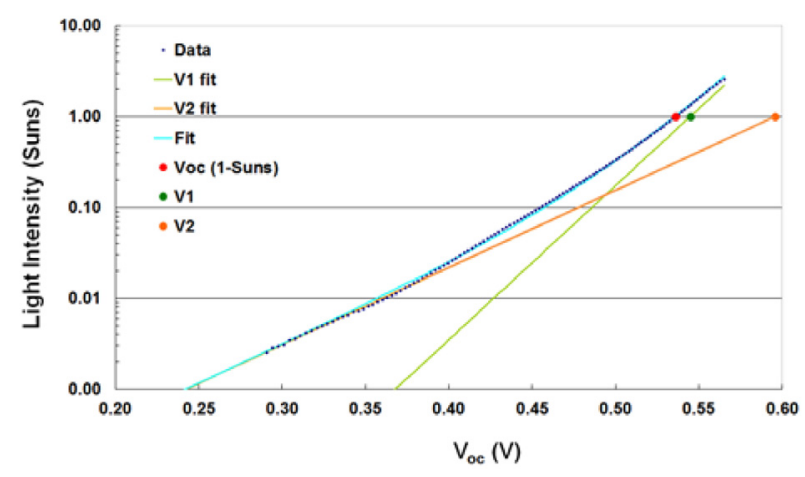

(a)

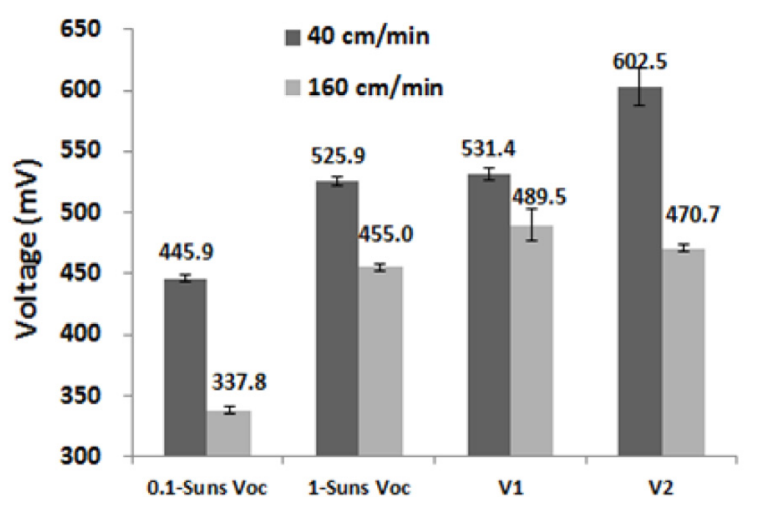

(b)

Fig. 8. (a) Suns- $V_{o c}$ measurement of the laser crystallized solar cells $\left(40 \mathrm{~cm} / \mathrm{min}\right.$ with $\left.15476 \mathrm{~W} / \mathrm{cm}^{2}\right)$ with fitted curve. (b) Suns- $V_{o c}$ results of scan speed of 40 and $160 \mathrm{~cm} / \mathrm{min}$.

\subsection{Solar cell performance and effects of film cracks}

It is clear that large cracks, width up to several hundred microns and length up to several millimeters are generated along the scan direction as shown in Figure 9. The position of the crack formation is random. In some case, few centimeters long cracks could be generated in right middle or near to the edges of the crystallized area. The cracks are always generated during the laser crystallization process and likely responsible for shunting problem when $p$ - $n$ junction is formed and metallized. It is shown that grain boundaries continue even after the crack which implies that the crack occurred after the film is solidified. Also, structural defects are often observed near the crack which is not surprising since the crack is likely to be formed by excessive tensile stress in the film. The stress could be responsible from high undercooling rate as well as the spatial non-uniformity of the undercooling rate. Solar cell device is fabricated on absorber layer crystallized at scan speed of $80 \mathrm{~cm} / \mathrm{min}$ by RTA emitter diffusion. After hydrogen passivation, the material is metallized using the point contacts. Figure 10 compares two types of cells, one with few severe cracks running through the middle of entire active area of the cells and one that the active area is made in the region of no crack. As can be seen, shunt resistance of the cell without cracks is around two times higher for the cell with cracks. Also, $V_{o c}$ and $J_{s c}$, and $F F$ 

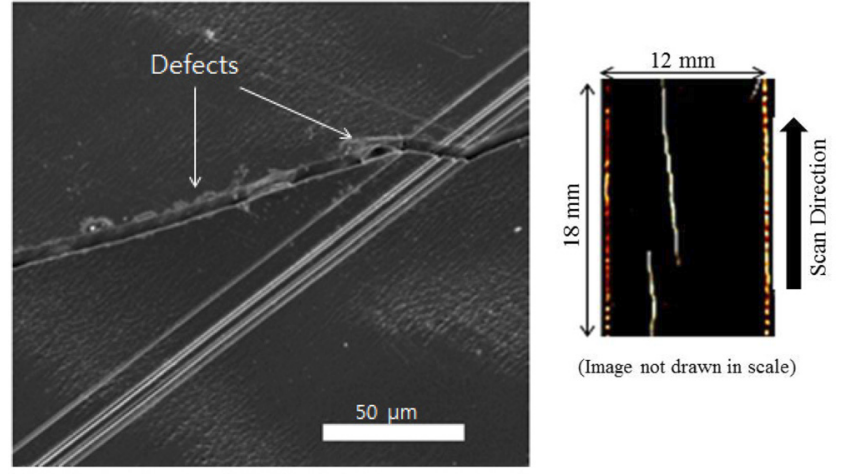

(Image not drawn in scale)

Fig. 9. (Left) SEM image of cracked region and (right) real image of cracks.

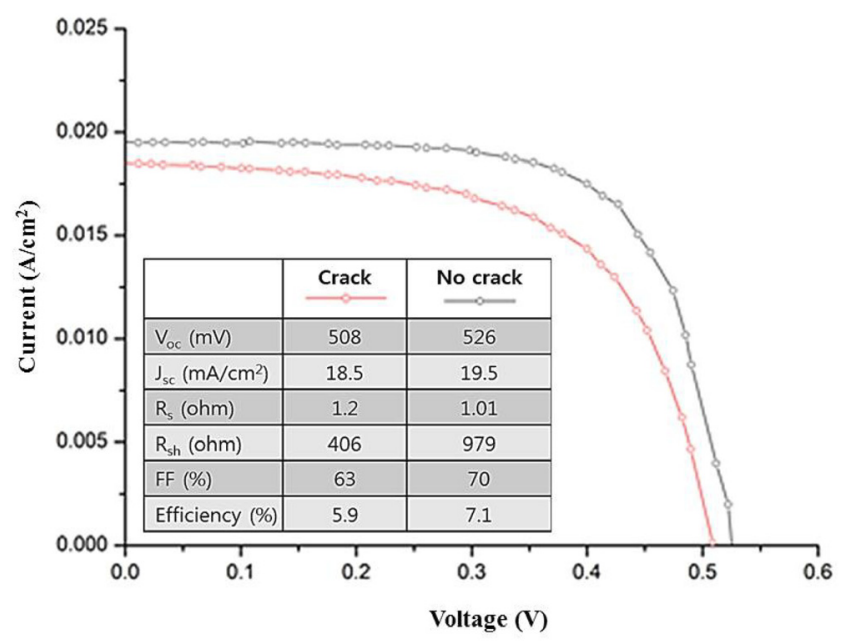

Fig. 10. Light $I-V$ curve comparison of solar cells with cracks and without cracks.

are lower for the cell with cracks. Overall efficiency is also reduced from $7.1 \%$ to $5.9 \%$ due to the cracks. Film cracking presents a major challenge for the laser crystallization of thin-film on glass.

\section{Conclusions}

High quality polycrystalline Si thin-film on glass was fabricated using CW diode laser crystallization. It was necessary to melt the entire silicon thin-film to obtain desired microstructure. When scanning speed was between 150 to $100 \mathrm{~cm} / \mathrm{min}$, large linear grains were formed, up to few tenths of millimeters in length and up to several hundred microns in width. Grain growth ceased when adjacent grains meet. High density of parallel grain boundaries is present frequently which was found to be twin boundaries. $\mathrm{SiO}_{x}$ capping layer is found to be effective in reducing the required laser power density to achieve fullmelting of the film. Also, preferred orientation is changed to (100) from (110) in surface normal direction when the capping layer is used. Two types of growth behaviors, Type I and Type II, are identified in respect to laser scan speed. In Type II (over $100 \mathrm{~cm} / \mathrm{min}$ ) growth behavior the solid and liquid phase region was shortened compared to that of Type I $(15-100 \mathrm{~cm} / \mathrm{min})$. As a result, grains growth could not follow the scan direction and tilted away from the scan direction. Suns- $V_{o c}$ measurement showed that band to band recombination was dominant for Type I while grain boundary recombination was dominant for Type II. Cracks are generated during the laser crystallization and it was found to reduce solar cell efficiency from $7.1 \%$ to $5.9 \%$.

This program has been supported by the Australian Government through the Australian Renewable Energy Agency (ARENA). The Australian Government, through ARENA, is supporting Australian research and development in solar photovoltaic and solar thermal technologies to help solar power become cost competitive with other energy sources. The views expressed herein are not necessarily the views of the Australian Government, and the Australian Government does not accept responsibility for any information or advice contained herein. Jae Sung Yun acknowledges support from the Australian Government through the Australian Solar Institute ARENA scholarship.

\section{References}

1. M.J. Keevers et al., in 22nd European Photovoltaic Solar Energy Conference, Milan, 2007

2. J. Wong et al., J. Appl. Phys. 107, 123705 (2010)

3. B. Eggleston et al., in MRS Online Proc. Library (Cambridge University Press, 2012), Vol. 1426

4. J. Dore et al., EPJ Photovoltaics 4, 40301 (2013)

5. J. Dore et al., Progr. Photovolt.: Res. Appl. 21, 1377 (2013)

6. W. Yeh, M. Matsumura, Jpn J. Appl. Phys. 41, 1909 (2002)

7. R. Vikas et al., Jpn J. Appl. Phys. 45, 4340 (2006)

8. H. Atwater, C.V. Thompson, H.I. Smith, J. Mater. Res. 3, $1232(1988)$

9. D. Witte et al., J. Vacuum Sci. Technol. B 26, 2455 (2008)

10. S.I. Sulaiman, in Proceedings of the IEEE International Conference on Semiconductor Electronics, 2004

11. O. Kunz, Ph.D. thesis, University of New South Wales, 2009

Cite this article as: Jae Sung Yun, Cha Ho Ahn, Miga Jung, Jialiang Huang, Kyung Hun Kim, Sergey Varlamov, Martin A. Green, Diode laser crystallization processes of Si thin-film solar cells on glass, EPJ Photovoltaics 5, 55204 (2014). 